Fracture and Structural Integrity: ten years of Frattura ed Integrita Strutturale'

\title{
The effect of low-cycle fatigue on evolution of fracture mechanics parameters in residual stress field caused by cold hole expansion
}

\author{
Yu. G. Matvienko \\ Mechanical Engineering Research Institute of the Russian Academy of Science (IMASH RAN). 4 M. Kharitonievsky Per., \\ 101990 Moscow, Russia \\ matvienko7@yahoo.com. \\ V.S. Pisarev, S. I. Eleonsky \\ Central Aero-Hydrodynamics Institute named after Prof. N.E. Zhukovsky (Ts AGI). 1 Zhukovsky Street, Zhukovsky 140180 \\ Moscow Region, Russia. \\ VSP5335@mail.ru, bttps://orcid.org/0000-0002-5378-609X \\ juгzepka@mail.ru, bttps://orcid.org/0000-0003-4345-067X
}

\begin{abstract}
Localized displacement measurements based on electronic speckle-pattern interferometry are used to obtain crack mouth opening displacement (CMOD), stress intensity factor (SIF) and T-stress values during crack growth around cold-expanded holes. The specimens with a central open hole are made from 2024 aluminium alloy. The expansion level is 5\% of nominal interference. The results are obtained for the same stress range $\Delta \sigma$ $=350 \mathrm{MPa}$, but different stress ratio $R=-0.4$ and $R=-1.0$. A sequence of narrow notches, inserted under the constant external load, serves for crack modelling at different stages of cyclic loading. Initial experimental data represent in-plane displacement component values measured in the vicinity of the crack tip. The transition from in-plane displacement components to SIF and T-stress values follows from the relationships of modified version of the crack compliance method. The crack length curves of CMOD, SIF and Tstress profiles are obtained for different stages of cyclic loading. These data provide the construction of dependencies of fracture mechanics parameters for cracks of fixed lengths from the loading cycle number.
\end{abstract}

KEYwORDS. Cold expansion; Crack growth; Crack mouth opening displacement; Stress intensity factor; T-stress.

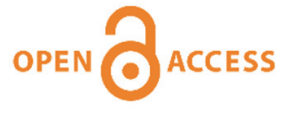

Citation: Matvienko, Yu. G., Pisarev, V. S., Eleonsky, S. I., The effect of low-cycle fatigue on evolution of fracture mechanics parameters in residual stress field caused by cold hole expansion, Frattura ed Integrità Strutturale, 47 (2019) 303-320.

Received: 11.09 .2018

Accepted: 29.11.2018

Published: 01.01.2019

Copyright: (C) 2019 This is an open access article under the terms of the CC-BY 4.0, which permits unrestricted use, distribution, and reproduction in any medium, provided the original author and source are credited. 


\section{INTRODUCTION}

$\mathrm{P}$

resent innovations in aircraft manufacture are based on advanced technologies. One of them is the cold expansion process that leads to enhance the fatigue life of structures with fastener holes [1]. The cold working introduces a zone of compressive residual stresses around the hole. Fatigue life improvement is mainly related to the circumferential residual stress influence that, firstly, delays the initial crack appearance increasing the damage tolerance life. Secondly, residual stress influence leads to reducing the effective range of stress intensity factor (SIF) decreasing fatigue crack growth rates [2-3].

Thus, it is generally agreed that residual stresses have a significant positive influence on fatigue life of structural components with cold expanded holes. However, the improvement in fatigue performance is difficult to quantify. Various techniques have been proposed in the literature to solve this problem. Theoretical methods of residual stress analysis, based on the study of analytical solutions in closed form, were developed in [4-6]. Numerical approaches were also created by using the finite element method in 2D or 3D formulation [7-12]. Most of these papers include experimental determination of residual stresses by non-destructive and destructive methods to obtain data that are essential for a validation of finite element simulation. Non-destructive experimental techniques are mainly related to X-ray diffraction [2]. Destructive (mechanical) methods of residual stress determination are based on local material removing [13-16].

Several experimental studies have considered the improvement in fatigue performance due to the presence of compressive residual stresses [17-19]. Fatigue predictions assume that the improvement arises because the crack is closed during part of the load cycle and therefore the effective range of stress intensity factor is reduced [8,20-21]. A set of works is devoted to an accurate analysis of SIF values for cracks located in the vicinity of cold expanded holes [22-24]. These data are essential for more realistic predictions of fatigue crack growth rates through the use of various models that are based on linear fracture mechanics and superposition principal [25-27]. The main problem of such an approach resides in the fact that the superposition principle may be erroneous when partial crack closure on the crack surfaces occurs. Thus, specific methodology has to be adopted to estimate the stress intensity factor as a result of the residual stress field influence. Moreover, the residual stress change due to fatigue loading should be taken into account.

One of the most typical approaches to an investigation of fatigue crack growth rates for cracks emanating from cold expanded holes is presented in [28]. The obtained experimental information is used for numerical simulation of residual stresses caused by elastic-plastic deformation of the hole. Experimental and numerical values of circumferential residual stress component averaged through the thickness are well matched. Three-dimensional finite element calculations of the SIF around a circular crack at the edge of a plain hole and a cold-expanded hole have been made. The dependencies of SIF at the mandrel entrance face vs. applied load for different corner crack lengths are obtained. Fatigue crack growth rates have been measured for cracks growing from plain holes and cold expanded holes. Comparison of measured fatigue crack growth rate of corner cracks with finite element predictions for different surface cracks lengths up to crack of $5 \mathrm{~mm}$ length is presented. Comparison of the finite element simulation and experimental measurement of "crack growth rate vs. crack length" showed an expected good agreement for the case of a plain hole with stress ratio $R=0.7$. For a plain hole with $R$ $=0.1$, the finite element simulation over-predicted the crack growth rate. For cold expanded holes, the agreement between simulation and measurement was only reasonable. Crack growth rate predictions are very sensitive to the calculation of stress intensity factor range. Such a calculation relies on a sufficiently accurate model of the material behaviour and a simulation of the cold expansion process, which is difficult to achieve.

Powerful approach to quantify the influence of cold-worked process on fatigue by numerical and experimental tests is proposed in [29]. The residual stress intensity factor for a crack emanating from cold-expanded hole is achieved through the use of weight function method [22]. The effective SIF vs. the crack length profiles are obtained for different expansion levels and for a plain hole. The crack propagation is evaluated with good approximation by finite-element method using a model in which compressive residual stress acts to reduce the crack opening SIF. The crack length curves as a function of the number of cycles for different maximum external loads $(R=0.1)$ are constructed.

Experimental investigations of crack growth process are of importance to create reliable methods inherent in fatigue life evaluation of cold-expanded holes. A remarkable example of such a study of very high methodological and technical level is presented in [30]. Non-contact full-field strain measurements by combined using digital image correlation (DIC) and thermoelastic stress analysis (TSA) were used to compare the strains during crack growth around plain and cold-expanded holes. These two systems provide the measurements of simultaneous mandrel entry (DIC) and exit (TSA) surface strains surrounding a crack initiating from a cold-expanded hole. Crack opening displacements, evaluated from the strain data obtained from DIC, are substantially reduced by the residual compressive stresses from cold expansion, while the overall fatigue data show the life improvement achieved at various applied stress levels. The most important outcome consists of 
dependencies between crack opening displacements and fatigue crack length constructed for crack lengths of 1, 2 and 3.7 $\mathrm{mm}$ for coupons with plain and cold-expanded holes.

Very interesting and powerful experimental approach aimed to describing residual stress evolution due to cyclic loading by the crack compliance (slitting) method is presented in Ref. [31]. Residual stress measurements were made in aluminium 7075-T651 plates with cold expanded holes. Residual stresses are represented by symmetric Legendre polynomials on opposite sides of the hole and compliance functions found by finite element analysis. Measured residual stresses were smaller than predicted by finite element analysis. Residual stress relaxation caused by cyclic loading was not observed even though two short cracks were formed between 45,000 and 50,000 cycles in the specimen cycled at $\sigma_{\max }=205 \mathrm{MPa}$ and $R=0.1$. The yield stress and ultimate tensile strength of 7075-T651 aluminium alloy were 541 and $568 \mathrm{MPa}$, respectively. The loading cycles parameters are the following. Stress ratio is $R=0.1$, maximum applied stress is $\sigma_{\max }=165.5,185.5$ and $205 \mathrm{MPa}$ that corresponds to $0.31,0.34$ and 0.38 of $\sigma_{y}$.

Above-presented review of published papers exhibits a wide spectrum of theoretical, numerical and experimental investigations of residual stresses near cold expanded holes, and how these stresses influence on fatigue life. It is established that residual stress variations must be taken into account in any potential model used for the prediction of fatigue life of cold-expanded holes. This fact reveals the main problem inherent in reliable and accurate numerical estimations of SIF values for cracks propagating in residual stress field caused be cold expansion of holes. Many works show that crack growth rate predictions are very sensitive to the calculation of the stress intensity factor range.

Thus, following by Prime's opinion, we can say that «Knowledge of residual stresses is crucial both for correct interpretation of laboratory fatigue crack growth experiments and for prediction of service failures. To be more specific, the resulting SIF is often of greater interest than the residual stresses themselves, because it appears directly in the fatigue crack growth and fracture relations» [32]. The last sentence is precisely true for a crack propagating from a cold-expanded hole in residual stress field.

There is the single approach to experimental determination of fracture mechanics parameters for cracks in residual stress field without preliminary determination of residual stress values. This technique, called as crack compliance method (CCM), is based on relaxation of the stress field by introducing a narrow notch of progressively increasing length. CCM employs measurement of the deformation response to a small crack length increment without changing external loading conditions. Schindler et al. developed the CCM version, which used fracture mechanics relations [33-34]. Only Schindler's method delivers the SIF as a function of crack length directly from the measured strains without first solving for the residual stresses. Published works do not include experimental data, which quantitatively describe an evolution of fracture mechanics parameters for cracks emanating from cold-expanded holes under cyclic loading. The most powerful way to solve this problem resides in experimental constructing of CMOD, SIF and T-stress curves as a function of number of cycles. A modified version of the crack compliance method is precisely the technique, which is capable of quantitative describing an evolution of fracture mechanics parameters for cracks under combined influence of residual stresses and applied cyclic stresses [35-36].

The present paper deals with determination of CMOD, SIF and T-stress values for cracks of different lengths emanating from centred open cold-expanded holes of $4 \mathrm{~mm}$ diameter in rectangular coupons. The expansion level is $5 \%$ of nominal interference. The results are obtained for two loading programs with the same stress range $\Delta \sigma=350 \mathrm{MPa}$ but different stress ratio $R=-0.4$ and $R=-1.0$. A sequence of narrow notches is used for crack modelling at different stages of cyclic loading. These notches are inserted under the constant external load. The experimental approach employs optical interferometric measurements of local deformation response to small notch length increment. Initial experimental data represent in-plane displacement component values measured by electronic speckle-pattern interferometry (ESPI) in the vicinity of the crack tip. Thus, CMOD values are derived directly. The transition from measured in-plane displacement components to required SIF and T-stress values follows from the relationships of modified version of the crack compliance method [33-34]. Dependencies of CMOD, SIF and T-stress values from total crack length are obtained for different stage of fatigue loading. These data give us CMOD, SIF and T-stress curves for cracks of fixed lengths as a function of the number of cycles.

\section{EXPERIMENTAL PROCEDURE}

\section{Specimens and loading program}

$\checkmark$ xperimental investigations are performed for 2024 aluminium plates measuring $180 \times 30 \times 5 \mathrm{~mm}^{3}$, each of which includes centred open hole of nominal diameter $2 r_{0}=4.0 \mathrm{~mm}$ (Fig. 1). Whole set of specimens includes 16 units. 
All coupons are manufactured from a single material bar by the same technology. Absence of residual stresses in all specimens is established by combining the hole drilling method and ESPI measurements of hole diameter increments in principal stress directions. Mechanical properties (elasticity modulus $E=74,000 \mathrm{MPa}$, yield stress $\sigma_{y}=330 \mathrm{MPa}$ and Poisson's ratio $\mu=0.33$ ) are measured by means of tensile tests.

Specimens are intended to be tested with cold-expanded holes. A tapered, cylindrical mandrel for the cold-worked process is adopted. The mandrel taper is 1:25 permitting a quite gradual application of loading pressure. Before forcing the hole, the mandrel external surface and internal hole surface are oiled to reduce the friction between the contact surfaces. The forcing load has been applied by using a testing machine with a speed equal to $1 \mathrm{~mm} / \mathrm{min}$. A split sleeve is not introduced because of a small plain hole diameter. The expansion level is $5 \%$ of nominal interference, defined as the ratio of the interference value to the hole radius. Optical measurements show increasing expanded hole diameter by $0.1 \mathrm{~mm}$ comparing with the plain hole diameter. The results of research [10], obtained by finite element simulation, evidence that the degree of interference from $4 \%$ to $6 \%$ leads to the arising circumferential residual stress $\sigma_{\text {res }}=-(250 \div 300)$ MPa at the expanded hole boundary. The exact value of $\sigma_{\text {res }}$ depends on the yield stress of aluminium alloy.

It is shown in many works that the residual stresses in the inlet surface are always lower than those measured in the outlet surface. This means that fatigue crack always originates from the hole edge corresponding to the inlet face where the lower compression residual stresses are arisen due to cold expansion. That is why optical interferometric measurements of the local deformation response to small notch length increment are performed in the mandrel entrance (inlet) surface of all specimens. Specimens are divided by two groups. The first of them, denoted as T5-H1, includes 8 specimens. The results are obtained at different stages of low-cycle fatigue with stress range $\Delta \sigma=350 \mathrm{MPa}$ and stress ratio $R=-0.4$. Maximum remote tensile stress for this loading program is equal to $\sigma_{\max }=250 \mathrm{MPa}$ that corresponds to 0.76 of yield stress $\sigma_{y}=330$ $\mathrm{MPa}$. Eight specimens from the second group (T5-H2) are tested at different stages of fatigue loading program with the parameters $\Delta \sigma=350 \mathrm{MPa}, R=-1.0$. The cycle parameters expressed in the terms of maximum tensile and minimum compressive stress are equal to $\sigma_{\max }=-\sigma_{\min }=175 \mathrm{MPa}$. The value of $\sigma_{\max }=175 \mathrm{MPa}$ corresponds to 0.53 of yield stress $\sigma_{y}=330 \mathrm{MPa}$.

To perform measurement procedure, specimens of both types are subjected to uniform uniaxial tension by electromechanical testing machine. All experimentally obtained parameters correspond to constant remote tension $\sigma=80.0 \mathrm{MPa}$. A choice of remote stress level is based on the following considerations. The most important initial experimental information is presented as crack opening displacements. Experimental design is arranged so to obtain a suitable fringe density in terms of $v$ displacement component for each from three crack length increments used. This means that a number of fringes for the first crack length should be relatively low. Then a fringe density subsequently increases for the second and the third crack length (see Fig. 1). In most of cases a fringe number is optimal for reliable quantitative interpretation for the second crack length. The third crack length displays the upper limit of fringe pattern resolution. Drawing of each specimen with loading conditions, co-ordinate system and notation used for in-plane displacement components are shown in Fig. 1. A sequence of narrow notches is used for crack modelling at different stages of fatigue loading. Step-by-step procedure of crack length increasing is performed by narrow jewellery saw of width $\Delta b=0.2 \mathrm{~mm}$. The original points of each symmetrical notch are located at the intersection of the hole boundary and the short symmetry axis of the specimen as it is shown in Fig. 1. The experimental approach employs optical interferometric measurements of the local deformation response to small notch length increment. Initial experimental data represent in-plane displacement component $u$ and $v$ measured by electronic speckle-pattern interferometry in the vicinity of the crack tip. Thus, CMOD values are derived directly. The transition from measured in-plane displacement components to required SIF and T-stress values follows from the relationships of modified version of the crack compliance method [35-36].

The first specimen, which is common for both groups, is tested before fatigue loading. Other specimens are subjected to fatigue loading according to the above-mentioned programs. An electro-mechanical testing machine walter + bai ag, Type LFM-Z 200, with loading range $0-200 \mathrm{kN}$ is used for fatigue loading. The number of loading cycles for each investigated specimen is listed in Tab. 1 and Tab. 2 for specimens of T5-H1 and T5-H2 group, respectively. Two specimens serve for lifetime estimation. Fracture of specimens is occurred after $N_{F 1}=6300$ cycles for specimen T5_H1 and $N_{F 2}=15800$ cycles for specimen T5-H2. Each specific cycle number from Tab. 1 and Tab. 2 indicates the stage of fatigue loading, at which CMOD, SIF and T-stress values are derived for cracks of different lengths from initial experimental data. Three consecutive notches after fatigue loading of specimens are inserted under the constant external load. An electro-mechanical testing machine walter + bai ag, Type LFM-L 25, with loading range 0-25 kN serves for applying remote tensile stress during the measurement procedure. 


\begin{tabular}{ccccccccc}
\hline Specimen & T5_20H & T5_13H & T5_16H & T5_12H & T5_18H & T5_19H & T5_17H & T5_H1 \\
$\begin{array}{c}\text { Number of } \\
\text { cycles, } N\end{array}$ & 0 & 1000 & 2000 & 3000 & 4000 & 5000 & 6000 & 6300 \\
Lifetime, $\%$ & 0 & 16 & 32 & 48 & 63 & 79 & 95 & 100 \\
\hline
\end{tabular}

Table 1: Nomenclature of T5-H1 specimens and fatigue loading program.

\begin{tabular}{cccccccccc}
\hline Specimen & T5_20 & T5_21 & T5_22 & T5_23 & T5_24 & T5_25 & T5_26 & T5_27 & T5_H2 \\
$\begin{array}{c}\text { Number of } \\
\text { cycles, } N\end{array}$ & 0 & 1000 & 2000 & 3000 & 6000 & 9000 & 12000 & 15000 & 15800 \\
Lifetime, $\%$ & 0 & 6 & 13 & 19 & 38 & 57 & 76 & 95 & 100 \\
\hline
\end{tabular}

Table 2: Nomenclature of T5-H2 specimens and fatigue loading program.
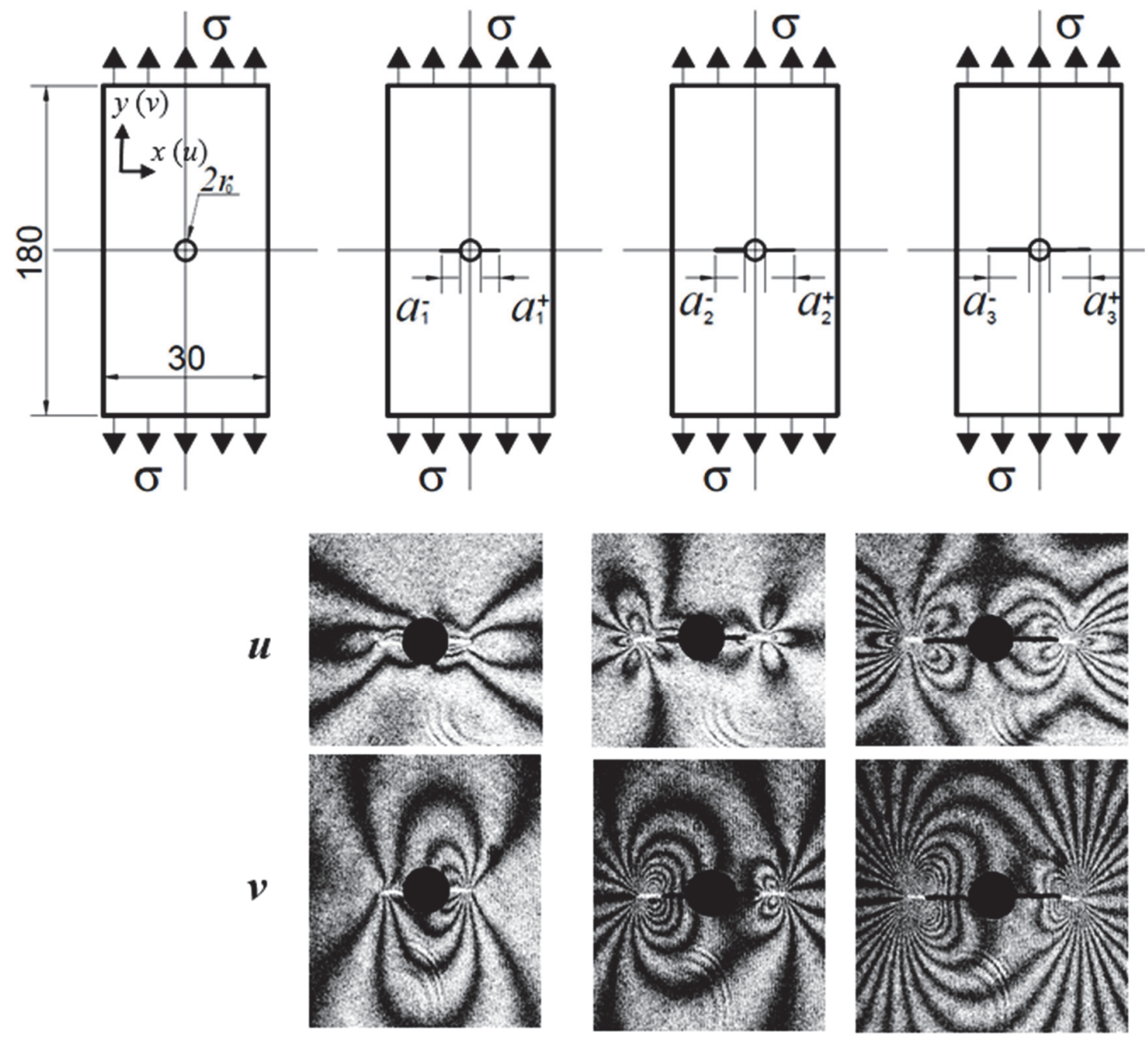

Figure 1: Scheme of consecutive notches at each measurement step and corresponding interference fringe patterns.

The details of the experimental procedure are presented in Ref. [36]. In short, the scheme of the experiment involved, conventionally shown in Fig. 1, resides in the following. Constant tensile load $P$ is applied to the specimen. The first exposure 
is made for the notch of current length $a_{n-1}(\mathrm{n}=1,2,3)$. After that, the notch length is increased by a small increment and the second exposure is made for the notch of final length. Constancy of acting force during the process of notch length increase lies in the interval $P-0.01 P$ with a warranty. Initial experimental information for each measurement step has a form of two interference fringe patterns related to in-plane displacement components $u$ and $v$ as it shown in Fig. 1. Presented interferograms are obtained for specimen T5_13H after applying $N=1000$ cycles.

\section{Initial experimental information}

Initial experimental information has the form of interference fringe patterns, which describe the distributions of both inplane displacement components near the crack tip. These interferograms correspond to increasing the length of the central symmetrical crack of mode I in thin rectangular plate under constant tensile load. The total crack length consists of three prolongation increments. Typical interference fringe patterns obtained for different notch length increments in specimens of T5-H1 and T5-H2 group are shown in Figs. 1, 2, and 3, 4, respectively. High quality of presented interferograms is quite evident.



a

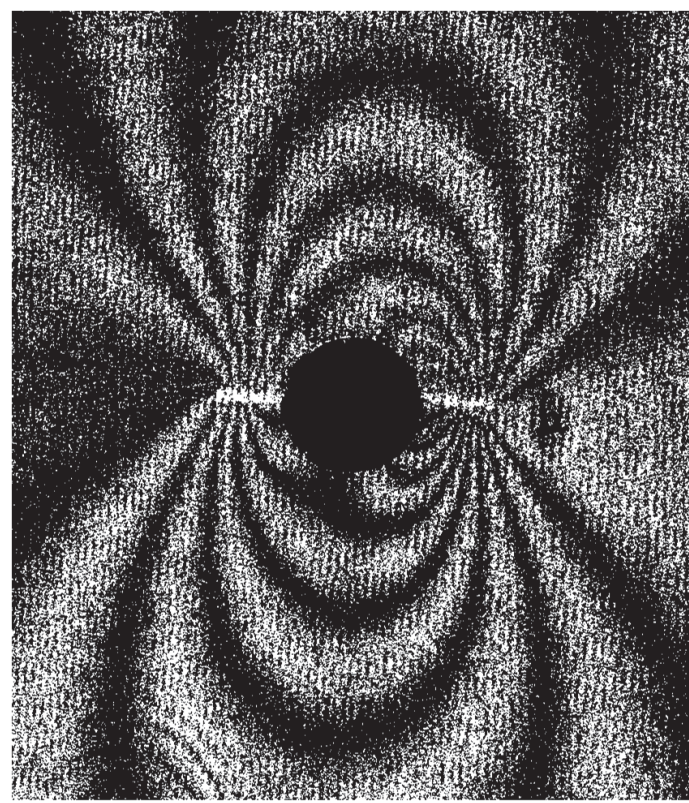

C

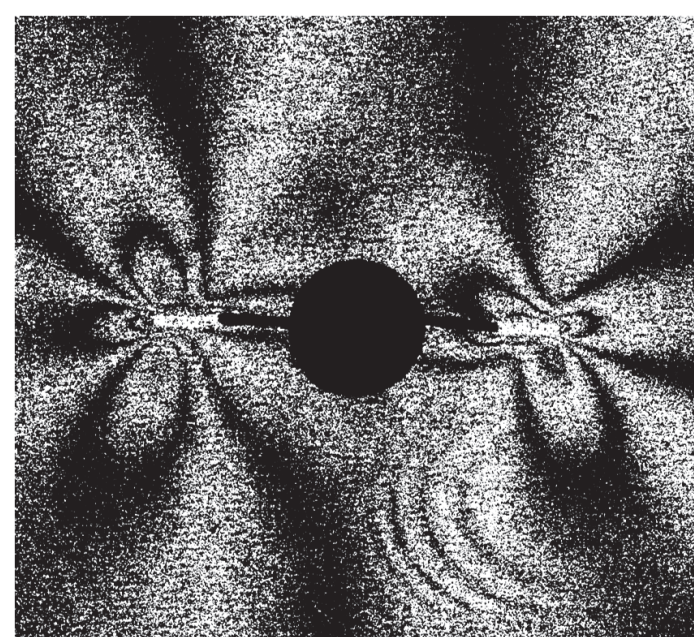

$\mathrm{b}$

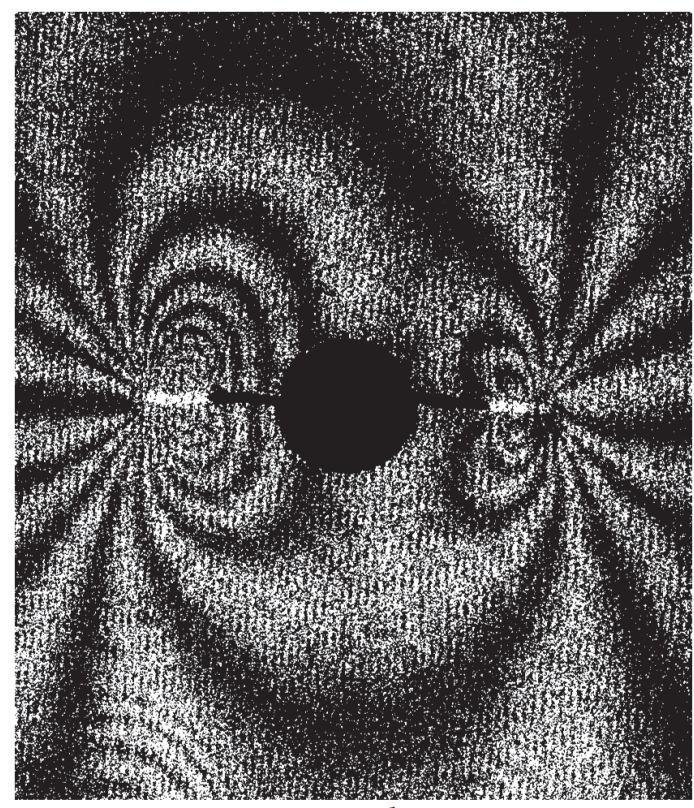

d

Figure 2: Specimen T5_18H. Interference fringe patterns obtained in terms of in-plane displacement component $u$ (a, b) and $v$ (c, d); a, $\mathrm{c}$ - initial crack length $a_{0}=0$ with the increment $\Delta a_{1}^{-}=1.97 \mathrm{~mm}$ (left) and $\Delta a_{1}^{+}=2.18 \mathrm{~mm}$ (right); b, $\mathrm{d}-$ initial crack length $a_{1}^{-}=$ 1.97 with the increment $\Delta a_{2}^{-}=1.87 \mathrm{~mm}$ (left) and initial crack length $a_{1}^{+}=2.18 \mathrm{~mm}$ with the increment $\Delta a_{2}^{+}=1.70 \mathrm{~mm}$ (right). 




a

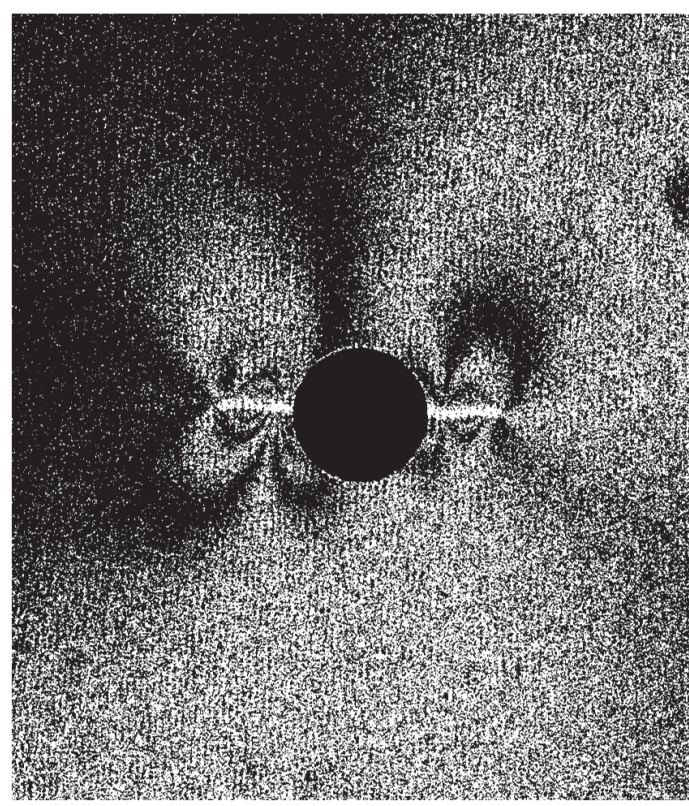

C

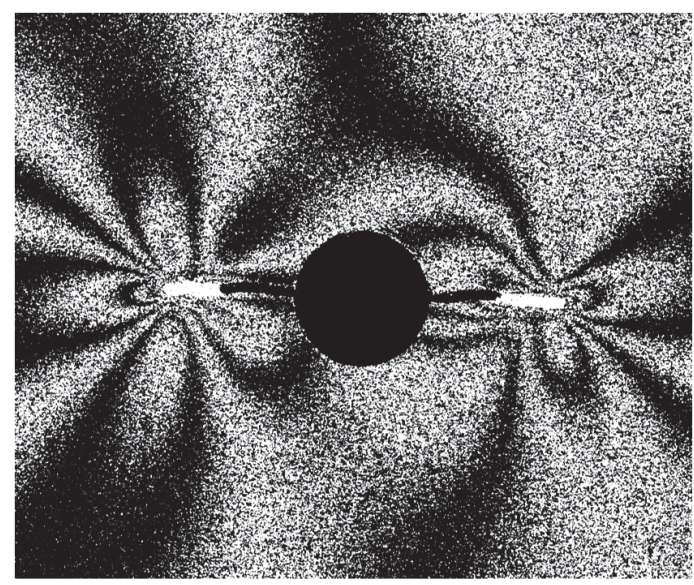

$\mathrm{b}$

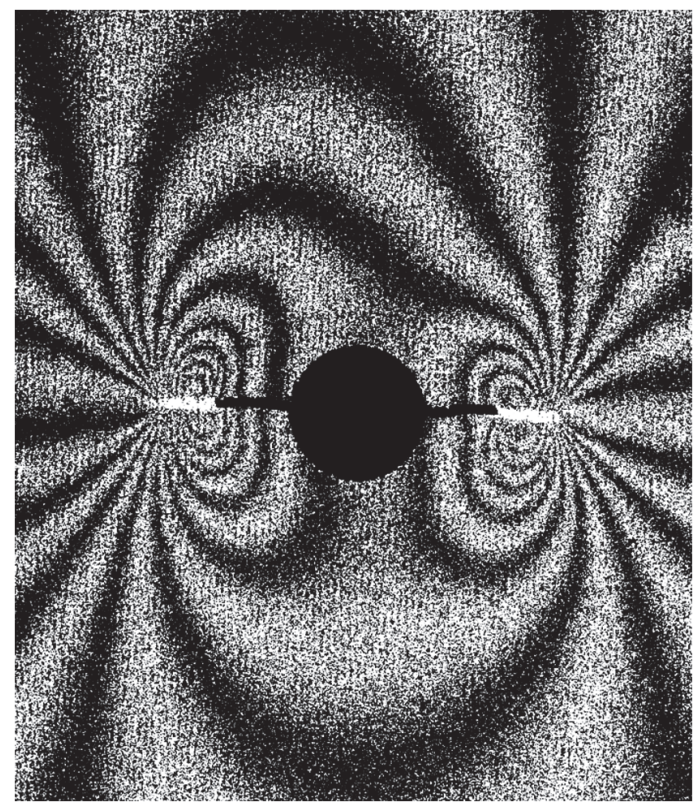

d

Figure 3: Specimen T5_21H. Interference fringe patterns obtained in terms of in-plane displacement component $u(\mathrm{a}, \mathrm{b})$ and $v(\mathrm{c}, \mathrm{d})$; a $\mathrm{c}$ - initial crack length $a_{0}=0$ with the increment $\Delta a_{1}^{-}=2.36 \mathrm{~mm}$ (left) and $\Delta a_{1}^{+}=2.35 \mathrm{~mm}$ (right); b, $\mathrm{d}-$ initial crack length $a_{1}^{-}=2.36$ $\mathrm{mm}$ with the increment $\Delta a_{2}^{-}=1.82 \mathrm{~mm}$ (left) and initial crack length $a_{1}^{+}=2.35 \mathrm{~mm}$ with the increment $\Delta a_{2}^{+}=1.96 \mathrm{~mm}$ (right).

Interference fringe patterns of the type shown in Figs. 1-4 are obtained for all specimens accordingly to both loading programs for three notch length increments. Thus, a total number of interferograms is equal to $2 \times 3 \times 14=84$ for specimens of both groups. Symmetrical configuration of fringe patterns in Figs. 1, 2 and 3, 4 with respect to the crack line clearly demonstrates the validity of mode I conditions. The same configuration takes place for all crack length increments for all specimens. This means that SIF and T-stress values can be reliably determined from the relationships developed for modified version of the crack compliance method [36].

\section{RESULTS AND DISCUSSION}

A choice of loading programs is based on the following. The cycle with parameters $\Delta \sigma=350 \mathrm{MPa}$ and $\mathrm{R}=-0.4$ gives maximum tensile and minimum compressive remote stress $\sigma_{\max }=250 \mathrm{MPa}$ and $\sigma_{\min }=-100 \mathrm{MPa}$, 
respectively. Maximum circumferential strain at the hole edge equals to $\varepsilon_{\phi \max }=0.01$ for $\sigma_{\max }=250 \mathrm{MPa}$. This loading range for this aluminium alloy leads to arising high-level plastic strains at the hole vicinity during several first cycles and further material hardening for specimens with small plain hole due to stress concentration influence [37]. The value of theoretical stress concentration factor for central open hole of diameter $2 r_{0}=4.0 \mathrm{~mm}$ in rectangular plate of width $w=30$ $\mathrm{mm}$ is equal to $K_{t}=3.06$ [38]. This fact might lead to a considerable residual stress and, in turn, fracture mechanics parameters redistribution for specimens of T5-H1 group due to low-cycle fatigue. The cycle with parameters $\Delta \sigma=350$ $\mathrm{MPa}$ and $\mathrm{R}=-1.0$ represents the lower limit of stress ratio values, which might take place during operations of airplane structures with pin or/and rivet joints.

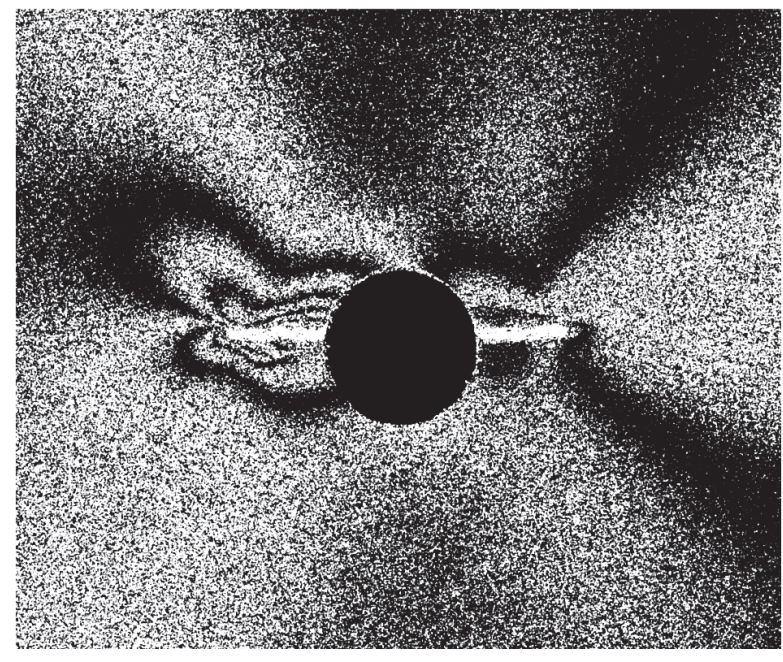

a



C



$\mathrm{b}$

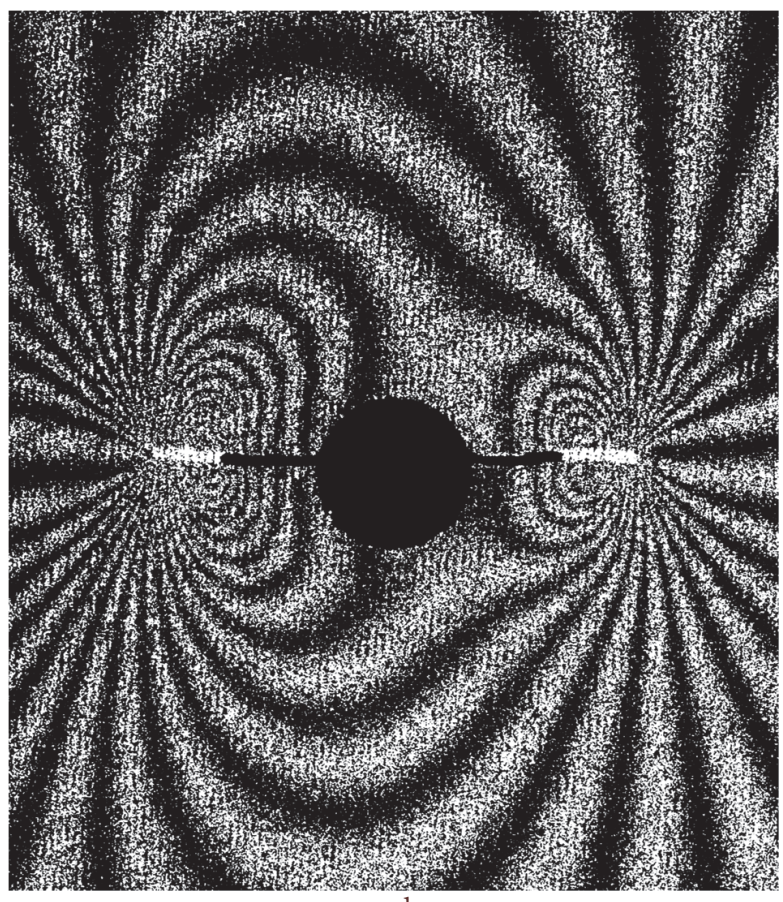

d

Figure 4: Specimen T5_25H. Interference fringe patterns obtained in terms of in-plane displacement component $u$ (a, b) and $v$ (c, d); a, $\mathrm{c}-$ initial crack length $a_{0}=0$ with the increment $\Delta a_{1}^{-}=2.62 \mathrm{~mm}$ (left) and $\Delta a_{1}^{+}=2.48 \mathrm{~mm}$ (right); b, $\mathrm{d}-$ initial crack length $a_{1}^{-}=2.62$ $\mathrm{mm}$ with the increment $\Delta a_{2}^{-}=1.82 \mathrm{~mm}$ (left) and initial crack length $a_{1}^{+}=2.48 \mathrm{~mm}$ with the increment $\Delta a_{2}^{+}=2.10 \mathrm{~mm}$ (right). 
Fracture mechanics parameters versus crack length

The whole set of the interference fringe patterns is the source of initial experimental data, which represent in-plane displacement components measured by electronic speckle-pattern interferometry in the vicinity of the crack tip. Availability of high-quality interference fringe patterns, which are free from rigid-body motion, serves as a reliable indicator of the real stress state near the crack tip. Some of these interferograms are presented in Figs. 1-4. Absolute values of in-plane displacement components $u$ and $v$ are determined in two specific points located at the crack borders immediately. The first point, denoted as $n-1$, lies in the beginning of each crack length increment. The second point $n-0.5$ is located in the middle of the crack length increment. Averaged crack mouth opening displacement (CMOD $\Delta \tilde{v}_{n-1}, \mathrm{n}=1,2,3$ ) together with crack opening displacement related to half of the crack length (COD $\Delta \tilde{v}_{n-0.5}$ ) are obtained for symmetrically centred cracks in all specimens of both types. These data are essential for the transition from the initial experimental data to the required SIF ( $\left.\tilde{K}_{I}^{n}, \mathrm{n}=1,2,3\right)$ and $\mathrm{T}$-stress $\left(\tilde{T}^{n}, \mathrm{n}=1,2\right)$ values by using the relationships of the modified version of the crack compliance method developed in [36]. Dependencies of CMOD, SIF and T-stress values from total crack length in specimens of both groups, constructed for different loading cycles, are shown in Figs. 5, 6 and 7, respectively.
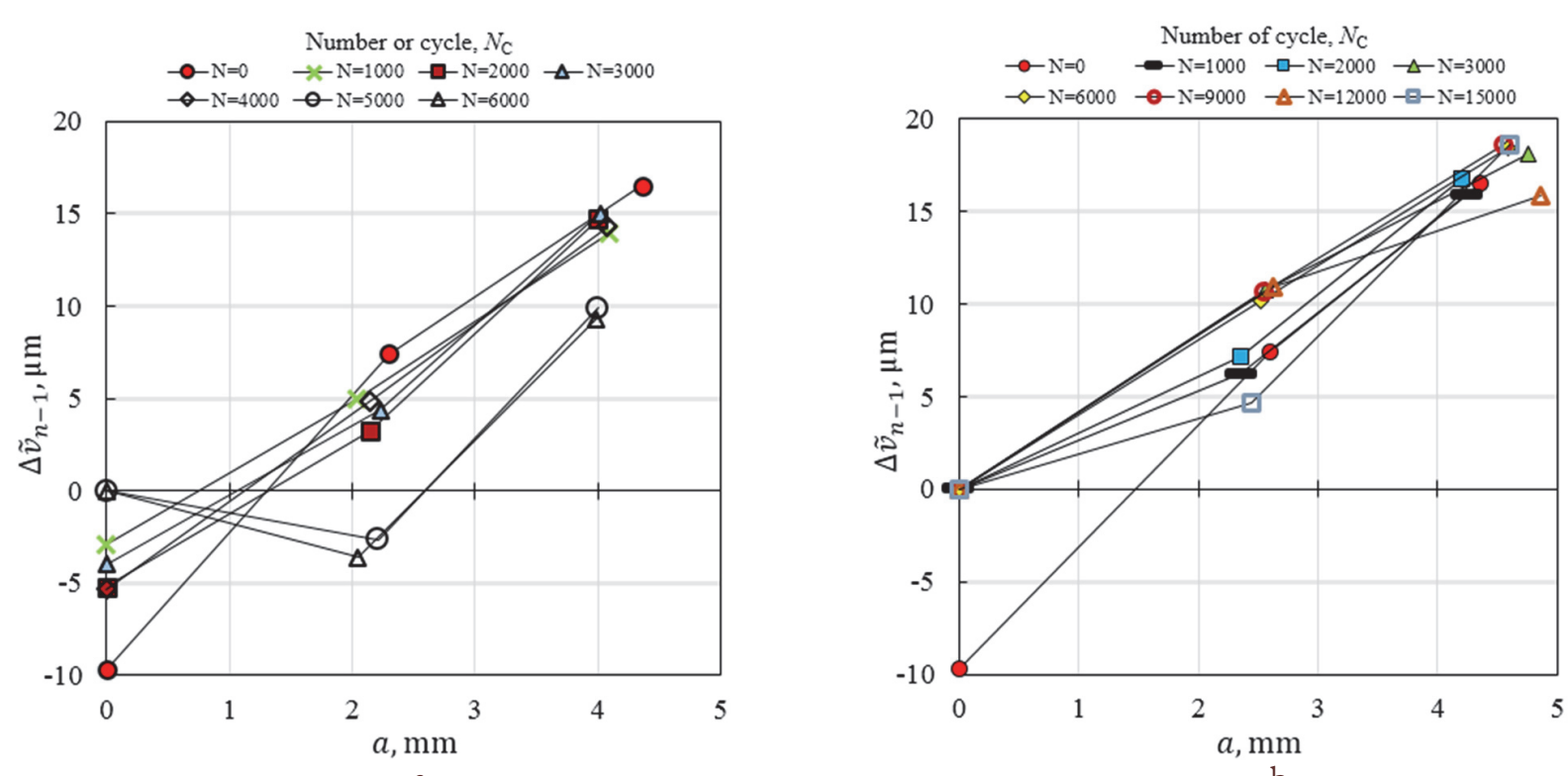

a

$\mathrm{b}$

Figure 5: CMOD values as a function of total crack length for specimens of T5-H1 (a) and T5-H2 (b) group.

T-stress dependencies along the crack length shown in Fig. 7 are presented as straight lines. This is because of three crack length increments $\left(\Delta a_{1}, \Delta a_{2}\right.$ and $\left.\Delta a_{3}\right)$ enable $\tilde{T}_{1}$ and $\tilde{T}_{2}$ can be only derived from experimental data [36]. Relative arrangement of these straight lines is of importance for further analysis.

Graphical information in Figs. 5a and 6a reveals indicators, which can be used for fatigue life assessment. Indeed, CMOD values $\Delta \tilde{v}_{0}$ related to the first crack length are equal to zero for $N=5000$ and $N=6000$ cycles (Fig. 5a). The second crack length demonstrates negative CMOD values $\Delta \tilde{\nu}_{1}$ for $N=5000$ and $N=6000$ cycles. Positive SIF value $\tilde{K}_{I}^{2}$ for $N$ $=5000$ cycles is less than positive SIF values at the other stages of fatigue loading (Fig. 6a). It is safe to assume that previous measurement point $N=4000$ cycles corresponds to reaching $63 \%$ of lifetime. This fact will be confirmed later in the next section. Negative SIF value for $N=6000$ cycles is related to $95 \%$ of lifetime. Note that no surface cracks were observed after applying $N=4000,5000$ and 6000 cycles. Fig. $5 \mathrm{~b}$ demonstrates that CMOD values for cracks of $\tilde{a}_{2}$ length, denoted as $\Delta \tilde{\nu}_{1}$, obtained for $N=3000,6000,9000$ and 12000 cycles are practically the same. But, graphical information in Fig. $6 \mathrm{~b}$ shows that SIF value $\tilde{K}_{I}^{2}$ for $N=9000$ cycles is more than SIF values for the second crack lengths $\tilde{a}_{2}$ at the other stages of fatigue loading. This indicator corresponds to reaching $57 \%$ of lifetime. 

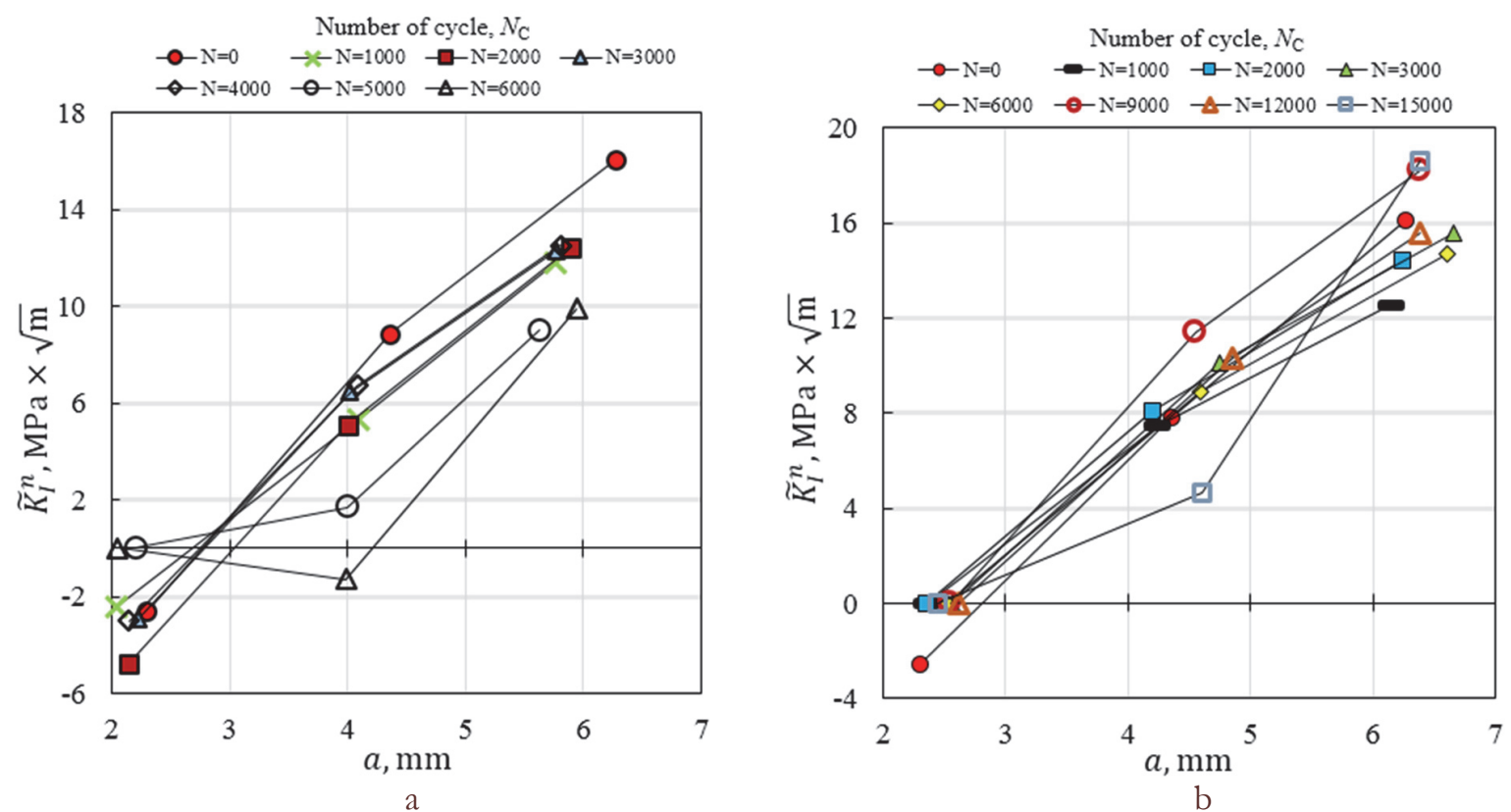

Figure 6: SIF values as a function of total crack length for specimens of T5-H1 (a) and T5-H2 (b) group.


Figure 7: T-stress values as a function of total crack length for specimens of T5-H1 (a) and T5-H2 (b) group.

\section{Fracture mechanics parameters versus loading cycle number}

To quantify the influence of stress ratio $R$ on fatigue life of cold expanded holes, the fracture mechanics parameters for cracks of the fixed length should be plotted against of the loading cycle number. The average values of CMOD, SIF and Tstress, presented in Tab. 3 and Tab. 4 for specimens of T5-H1 and T5-H2 type, respectively, are used to reach this purpose. Experimentally obtained values correspond to remote tensile stress $\sigma=80 \mathrm{MPa}$ for specimens of both groups. Dependencies of CMOD, SIF and T-stress values against of the loading cycle number for cracks of the fixed length are shown in Figs. 8-10. The loading cycle number in these figures is presented as a lifetime percentage. 
Yu. G. Matvienko et alii, Frattura ed Integrità Strutturale, 47 (2019) 303-320; DOI: 10.3221/IGF-ESIS.47.23

\begin{tabular}{cccccccc}
\hline $\begin{array}{c}\text { Specimen's } \\
\text { notation }\end{array}$ & T5_20H & T5_13H & T5_16H & T5_12H & T5_18H & T5_19H & T5_17H \\
$\begin{array}{c}\text { Loading cycle } \\
\text { number } N_{C}\end{array}$ & 0 & 1000 & 2000 & 3000 & 4000 & 5000 & 6000 \\
Lifetime, $\%$ & 0 & 16 & 32 & 48 & 63 & 79 & 95 \\
$\tilde{a}_{1}, \mathrm{~mm}$ & 2.30 & 2.04 & 2.14 & 2.23 & 2.15 & 2.21 & 2.05 \\
$\tilde{a}_{2}, \mathrm{~mm}$ & 4.36 & 4.09 & 4.0 & 4.02 & 4.08 & 4.0 & 4.00 \\
$\tilde{a}_{3}, \mathrm{~mm}$ & 6.27 & 5.76 & 5.89 & 5.77 & 5.81 & 5.63 & 5.94 \\
$\Delta \tilde{v}_{0}, \mu \mathrm{m}$ & -9.69 & -2.95 & -5.23 & -3.99 & -5.32 & 0 & 0 \\
$\Delta \tilde{v}_{1}, \mu \mathrm{m}$ & 7.41 & 4.94 & 3.23 & 4.37 & 4.85 & -2.66 & -3.61 \\
$\Delta \tilde{v}_{2}, \mu \mathrm{m}$ & 16.53 & 13.97 & 14.73 & 15.01 & 14.30 & 9.88 & 9.31 \\
$\tilde{K}_{I}^{1}, \mathrm{MPa} \times \sqrt{\mathrm{m}}$ & -2.6 & -2.4 & -4.8 & -2.9 & -3.0 & 0 & 0 \\
$\tilde{K}_{I}^{2}, \mathrm{MPa} \times \sqrt{\mathrm{m}}$ & 8.85 & 5.3 & 5.1 & 6.45 & 6.7 & 1.7 & -1.3 \\
$\tilde{K}_{I}^{3}, \mathrm{MPa} \times \sqrt{\mathrm{m}}$ & 16.05 & 11.8 & 12.4 & 12.3 & 12.5 & 9.0 & 9.9 \\
$\tilde{T}^{1}, \mathrm{MPa}$ & -58.7 & -4.0 & 15.8 & 6.3 & -10.8 & -14.6 & -14.3 \\
$\tilde{T}^{2}, \mathrm{MPa}$ & -141.8 & -136.9 & -95.5 & -142.1 & -121.6 & -96.5 & -65.3 \\
\hline
\end{tabular}

Table 3: Nomenclature of T5-H1 specimens and the cycle number.

\begin{tabular}{cccccccc}
\hline $\begin{array}{c}\text { Specimen's } \\
\text { notation }\end{array}$ & T5_21H & T5_22H & T5_23H & T5_24H & T5_25H & T5_26H & T5_27H \\
$\begin{array}{c}\text { Loading cycle } \\
\text { number } N_{C}\end{array}$ & 1000 & 2000 & 3000 & 6000 & 9000 & 12000 & 15000 \\
Lifetime, $\%$ & 0.063 & 0.13 & 0.19 & 0.38 & 0.57 & 0.76 & 0.95 \\
$\tilde{a}_{1}, \mathrm{~mm}$ & 2.36 & 2.35 & 2.56 & 2.52 & 2.55 & 2.62 & 2.44 \\
$\tilde{a}_{2}, \mathrm{~mm}$ & 4.25 & 4.20 & 4.75 & 4.59 & 4.55 & 4.86 & 6.60 \\
$\tilde{a}_{3}, \mathrm{~mm}$ & 6.16 & 6.24 & 6.66 & 6.61 & 6.38 & 6.39 & 8.39 \\
$\Delta \tilde{\nu}_{0}, \mu \mathrm{m}$ & 0 & 0 & 0 & 0 & 0 & 0 & 0 \\
$\Delta \tilde{\nu}_{1}, \mu \mathrm{m}$ & 6.2 & 7.13 & 10.74 & 10.17 & 10.64 & 10.93 & 4.66 \\
$\Delta \tilde{\nu}_{2}, \mu \mathrm{m}$ & 15.9 & 16.72 & 18.05 & 18.43 & 18.61 & 15.87 & 18.62 \\
$\tilde{K}_{I}^{1}, \mathrm{MPa} \times \sqrt{\mathrm{m}}$ & 0 & 0 & 0 & 0 & 0 & 0 & 0 \\
$\tilde{K}_{I}^{2}, \mathrm{MPa} \times \sqrt{\mathrm{m}}$ & 7.5 & 8.1 & 10.1 & 8.9 & 11.4 & 10.3 & 3.4 \\
$\tilde{K}_{I}^{3}, \mathrm{MPa} \times \sqrt{\mathrm{m}}$ & 12.6 & 14.4 & 15.6 & 14.7 & 18.2 & 15.6 & 18.8 \\
$\tilde{T}^{1}, \mathrm{MPa}$ & -28.9 & -34.2 & -38.2 & -39.2 & -47.9 & -45.6 & -31.6 \\
$\tilde{T}^{2}, \mathrm{MPa}$ & -129.6 & -124.7 & -162.3 & -138.0 & -167.5 & -197.2 & -104.0 \\
\hline
\end{tabular}

Table 4: Nomenclature of T5-H2 specimens and the cycle number. 


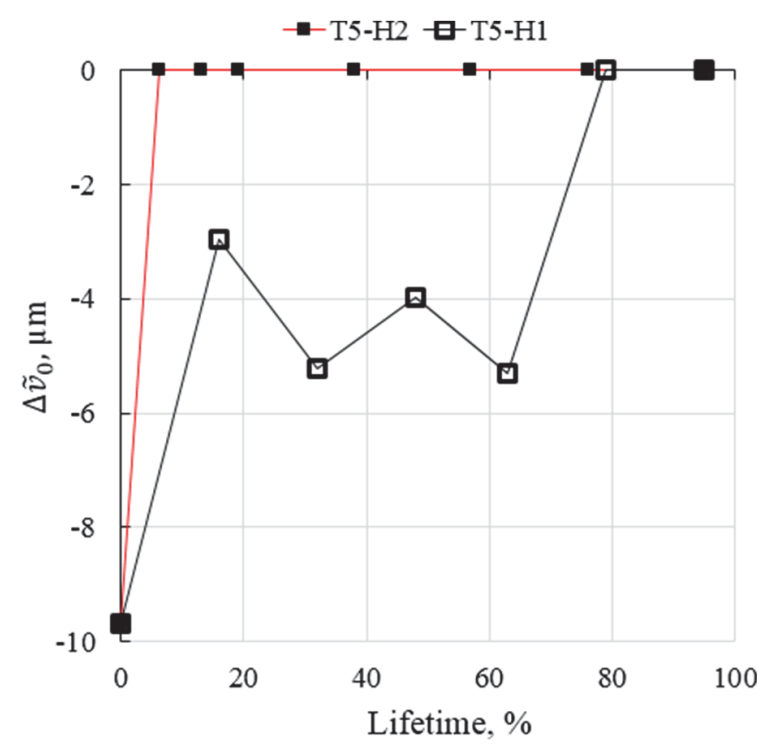

a



b

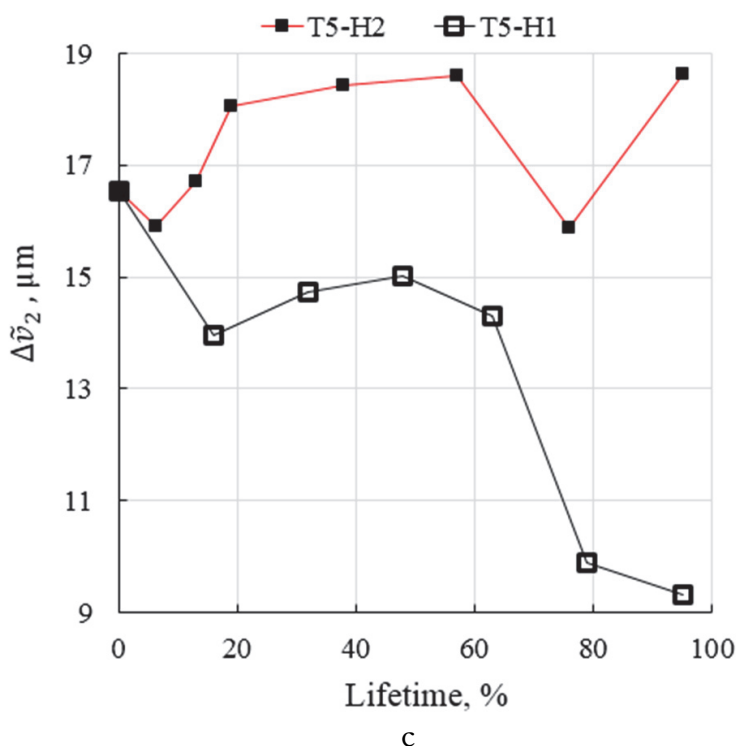

Figure 8: Experimental CMOD values $\Delta \tilde{v}_{0}$ (a), $\Delta \tilde{v}_{1}$ (b) and $\Delta \tilde{v}_{2}$ (c) for cracks of $\tilde{a}_{1}, \tilde{a}_{2}$ and $\tilde{a}_{3}$ length as a function of lifetime percentage for specimens of $\mathrm{T} 5-\mathrm{H} 1$ and $\mathrm{T} 5-\mathrm{H} 2$ group.

Figs. 8 and 9 demonstrate the effect of stress ratio $R$ on the redistribution of CMOD and SIF as the result of low-cycle fatigue with the same stress range. Comparative analysis of these distributions indicates a considerable difference in the CMOD and SIF values for all crack lengths. As expected, CMOD and SIF values for T5-H1 specimens are much below these values for T5-H2 specimens. The point is that increasing CMOD and SIF values for a narrow notch inserted under constant tensile loading means decreasing a rate of real damage accumulation process inherent in cyclic loading. Experimental SIF vs. the fatigue cycle number curves for T5-H1 specimens exhibit $63 \%$ lifetime indicator as a point of SIF fall beginning for $N_{H 1}=4000$ cycles. This point is reliably detected as it is shown by vertical black line in Fig. $9 \mathrm{a}$. The same situation takes place for specimens of T5-H2 group. The point of SIF fall beginning in Fig. 9b means reaching 57\% of lifetime for $N_{H_{2}}=9000$ cycles as it is shown by vertical red line in Fig. 9a. It is of importance for further investigations that reliable lifetime indicators are practically the same for specimens of both groups. This fact means that $60 \%$ lifetime indicator does not depend on a value of stress ratio $R$. The fracture occurred after $N_{F 1}=6300$ cycles and $N_{F 2}=15800$ cycles for specimens of T5-H1 and T5-H1 group, respectively. Thus, the life extension parameter is equal to 
$k_{100}=N_{F 2} / N_{F 1}=2.51$. It is necessary to note that a ratio between $60 \%$ lifetime indicators for specimens of different groups has very close value, namely, $k_{60}=N_{H 2} / N_{H 1}=2.25$.



a

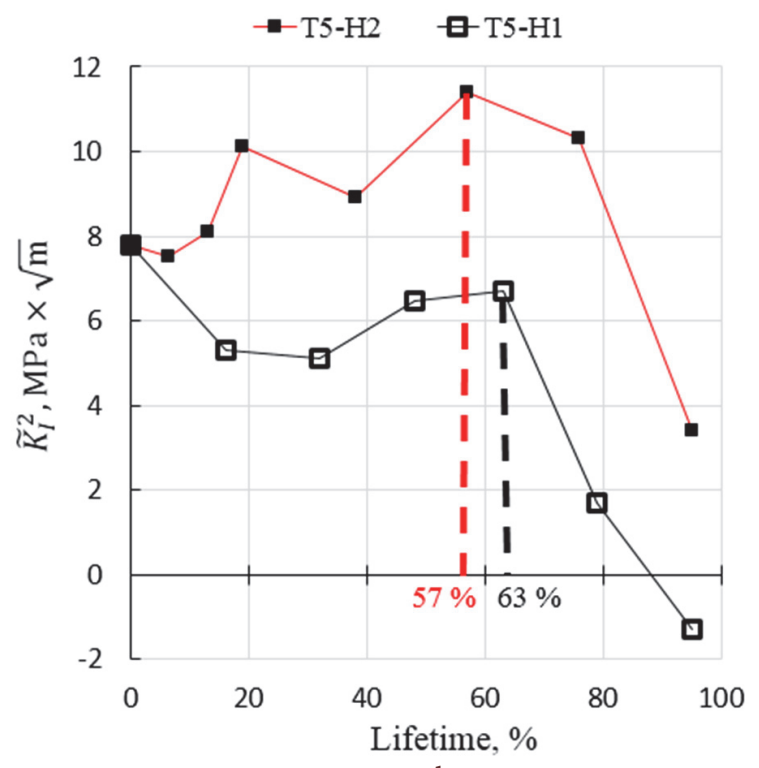

$\mathrm{b}$

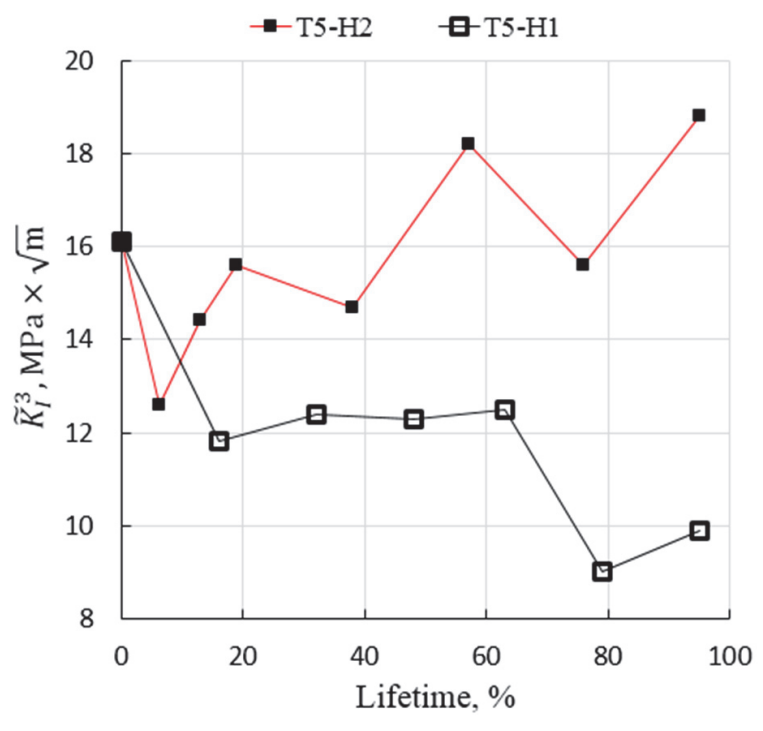

c

Figure 9: Experimental SIF values $\tilde{K}_{I}^{1}$ (a), $\tilde{K}_{I}^{2}$ (b) and $\tilde{K}_{I}^{3}$ (c) for cracks of $\tilde{a}_{1}, \tilde{a}_{2}$ and $\tilde{a}_{3}$ length as a function of lifetime percentage for specimens of T5-H1 and T5-H2 group.

CMOD values for the first crack length are connected with circumferential compressive stresses caused by cold hole expansion. Comparing CMOD distributions in Fig. 8a reveals residual stress relaxation for specimens of T5-H1 group. But there is no residual stress redistribution for $N>1000$ cycles for T5-H2 specimens.

Fig. 10 concentrates on the effect of low-cycle fatigue on T-stress redistribution. The value of $T$ is the stress acting parallel to the crack plane in the direction of crack extension with a magnitude proportional to the applied nominal stress. The nonsingular term $T$ represents a tension or compression stress. Positive T-stress strengthens the level of crack tip stress triaxility 
and leads to high crack tip constraint, while negative T-stress leads to the lost of constraint. Fig. 10a evidences that for specimens of T5-H2 group $(R=-1)$ cracks of $\tilde{a}_{1}$ length have lower crack-tip constraint compared with constraint for specimens of T5-H1 group $(R=-0.4)$. Comparing T-stress values related to T5-H1 and T5-H2 specimens obtained for the second crack length $\tilde{a}_{2}$ demonstrates the opposite trend. Namely, negative T-stress values for T5-H1 group lie significantly below analogous data for $\mathrm{T} 5-\mathrm{H} 2$ specimens. These facts show that two-parameter fracture mechanics criteria are of great importance for cracks propagating under combined influence of external and residual stresses.

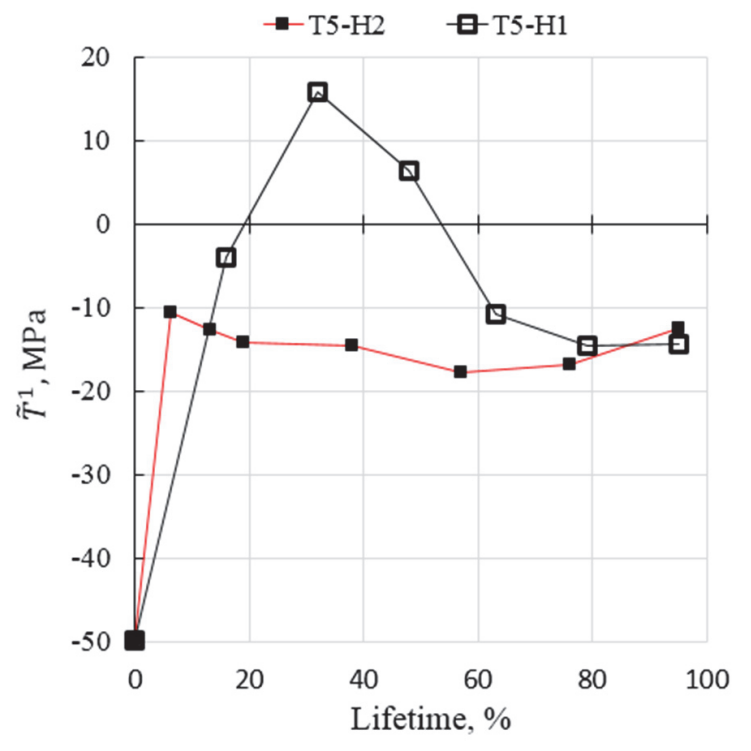

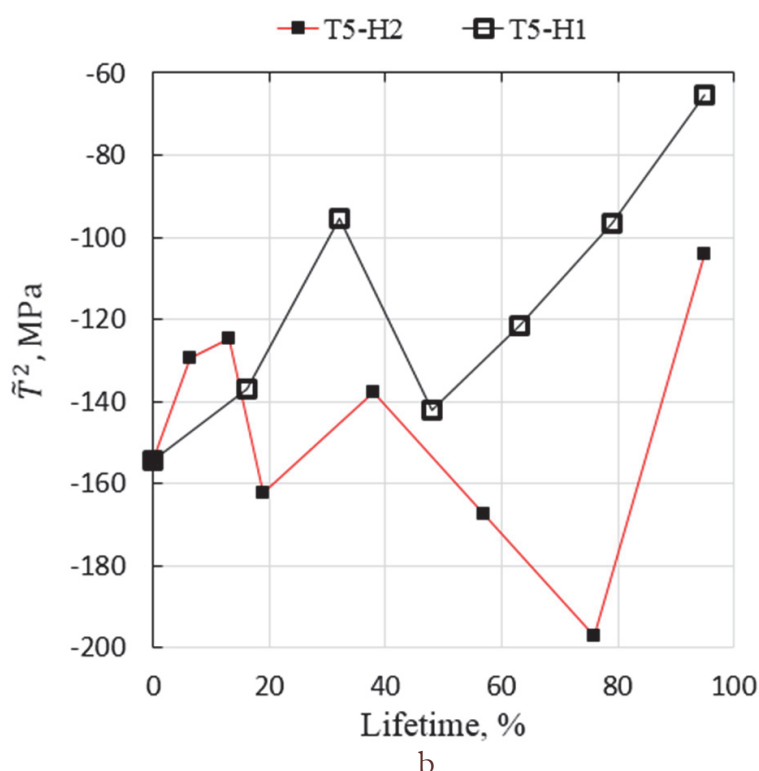

$\mathrm{b}$

Figure 10: Experimental T-stress values $\tilde{T}^{1}$ (a) and $\tilde{T}^{2}$ (b) for cracks of $\tilde{a}_{1}$ and $\tilde{a}_{2}$ length as a function of lifetime percentage for specimens of T5-H1 and T5-H2 group.

\section{Damage accumulation process}

Above-presented data describe an evolution of fracture mechanics parameters for specimens of two groups, which are loaded with the same stress range $\Delta \sigma=350 \mathrm{MPa}$, but with different stress ratio $\mathrm{R}=-0.4$ (T5-H1 group) and $R=-1.0$ (T5-H2 group). These experimental results are obtained for the same remote constant stress $\sigma=80 \mathrm{MPa}$ that corresponds to $24 \%$ of material yield stress $\sigma_{y}=330 \mathrm{MPa}$. Maximum cyclic stresses are equal to $\sigma_{\max }=250 \mathrm{MPa}$ and $\sigma_{\max }=175$

$\mathrm{MPa}$ that corresponds to $76 \%$ and $53 \%$ of yield stress for $\mathrm{T} 5-\mathrm{H} 1$ and $\mathrm{T} 5-\mathrm{H} 2$ group, respectively. Owing to this, maximum elastic-plastic circumferential strains at the hole vicinity caused by a stress concentration influence under external tensile load in specimens of T5-H1 group are much more than analogous strains in specimens of T5-H2 group. Stain concentration effect is valid, especially at initial stages of cyclic loading, despite of an influence of negative circumferential residual stresses due to cold hole expansion as it follows from Fig. 8a and 9a. This fact could mean that a rate of fatigue damage accumulation for specimens of T5-H1 group considerably exceeds analogous parameter for specimens of T5-H2 group. Thus, a correct comparison of fracture mechanics parameters, which are obtained in the case of the same stress range but different stress ratio, should be provided by a normalization of obtained experimental data. The most evident way resides in normalizing all data obtained for specimens of T5-H2 type by a coefficient that is equal to the life extension parameter

$$
k_{100}=N_{C F 2} / N_{C F 1}=2.51
$$

Distributions of normalized CMOD and SIF values for T5-H2 specimens over lifetime period are presented in Figs. 11 and 12. These figures also include CMOD and SIF values for T5-H1 specimens. A comparison of normalized SIF plots is of prime interest. The point is that these dependencies reflect the change in a process of fatigue damage accumulation as a result of stress ratio changing. To put it differently, normalized SIF distributions quantitatively describes how a decrease in 
negative value of cycle asymmetry ratio slows down fatigue damage accumulation process for loading programs with the same stress range.


Figure 11: Normalized CMOD values $\Delta \tilde{v}_{1}$ (a) and $\Delta \tilde{v}_{2}$ (b) for cracks of $\tilde{a}_{1}$ and $\tilde{a}_{2}$ length as a function of lifetime percentage for specimens of T5-H1 and T5-H2 group.

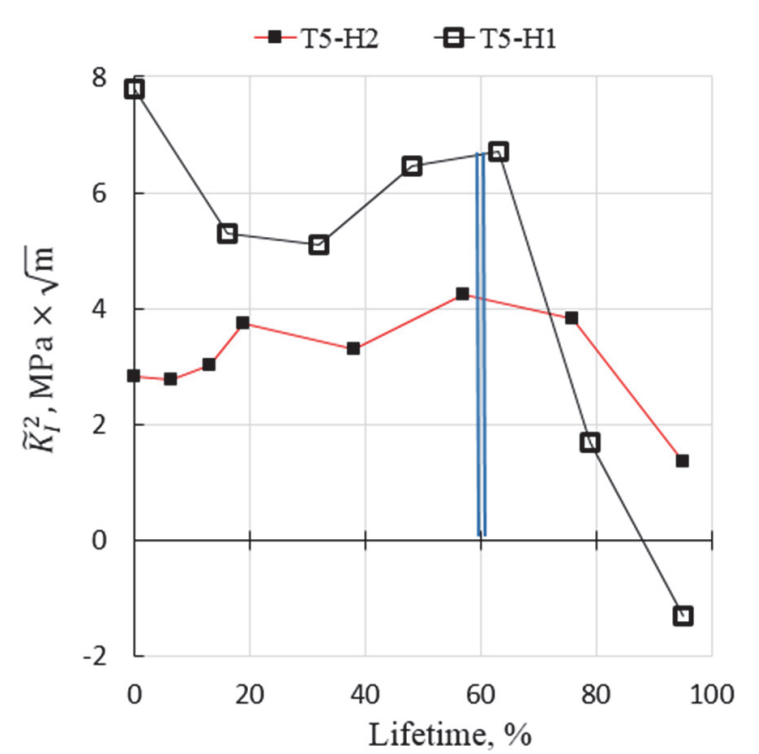

a



$\mathrm{b}$

Figure 12: Normalized SIF values $\tilde{K}_{I}^{2}$ (a) and $\tilde{K}_{I}^{3}$ (b) for cracks of $\tilde{a}_{1}$ and $\tilde{a}_{2}$ length as a function of lifetime percentage for specimens of T5-H1 and T5-H2 group.

The key point of the approach developed consists of the fact that specimens with cold-expanded holes are tested under real operation conditions without inserting initial notch to ensure fatigue crack growth. Deformation response to small notch length increment, made under constant external load, serves as an indicator of damage accumulation at different stages of fatigue loading. Thus, the first benefit of the crack compliance technique resides in a posteriori character of the experimental procedure. This means that crack length measurements and further determination of fracture mechanics parameters are performed after fatigue loading with a high degree of accuracy [36]. The second advantage is a capability of study of fatigue 
loading with negative stress ration despite of traditional approaches that operates with positive stress ratio values [2, 26, 2931, 39].

The third remarkable capability resides in quantitative determination of fracture mechanics parameters for cracks of different lengths at different stages of cyclic loading under combined influence of remote and residual stresses. These data provide the construction of the dependencies of the fracture mechanics parameters for cracks of fixed lengths against of the loading cycle number, which reveal a process of fatigue damage accumulation. Fracture mechanics parameters can be obtained for both the mandrel entry face and the mandrel exit face as well as for different stress range and stress ratio. Experimental information, if necessary, might be supplemented by data obtained for different remote stress levels to reveal a possible influence of non-linear effects.

\section{CONCLUSIONS}

$\mathrm{T}$ he effect of low-cycle fatigue on evolution of fracture mechanics parameters for cracks in residual stress field caused by cold expansion of holes has been analysed. To estimate the crack mouth opening displacement (CMOD), the stress intensity factor (SIF) and the T-stress during narrow notch increment, modelling a crack emanating from cold-expanded holes under constant external load, localized displacement measurements by electronic speckle-pattern interferometry are employed. Initial experimental data represent in-plane displacement component values measured in the vicinity of the crack tip. The transition from in-plane displacement components to SIF and T-stress values follows from the relationships of modified version of the crack compliance method. In general case, the preliminary low-cycle fatigue, namely, stress range and stress ratio, as well as crack length has strong effect on fracture mechanics parameters. The crack length curves of CMOD, SIF and T-stress profiles are obtained for cracks emanating from cold-expanded holes in plane specimens at different stages of cyclic loading with parameters $\Delta \sigma=350 \mathrm{MPa}, \mathrm{R}=-0.4$ and $\Delta \sigma=350 \mathrm{MPa}, \mathrm{R}=-1.0$. These data provide the construction of the dependencies of the fracture mechanics parameters for cracks of fixed lengths against the loading cycle number, which reveal a process of fatigue damage accumulation. Information is obtained in the mandrel inlet face. The results demonstrate considerable increase of fatigue damage accumulation process when $60 \%$ of the lifetime is reached. It is also shown that $60 \%$ lifetime indicator does not depend on the value of stress ratio $R$.

\section{ACKNOWLEDGEMENTS}

7 he authors acknowledge the support of the Russian Science Foundation (project N 18-19-00351).

\section{REFERENCES}

[1] Reid, L. (2014). Hole Cold Expansion - The Fatigue Mitigation Game Changer of the Past 50 Years, Advanced Materials Research, 891-892, pp. 679-684. DOI:10.4028/www.scientific.net/AMR.891-892.679.

[2] Stefanescu, D. (2004). Measurement and prediction of fatigue crack growth from cold expanded holes, part 1: the effect of fatigue crack growth on cold expansion residual stresses, J. of Str. Analysis, 39(1), pp. 25-39. DOI:10.1177/030932470403900103.

[3] Gopalakrishna, H.D., Narasimha Murthy, H.N., Krishna, M., Vinod, M.S., Suresh, A.V. (2010). Cold expansion of holes and resulting fatigue life enhancement and residual stresses in Al 2024T3 alloy - An experimental study, Eng. Failure Analysis, 17(2), pp. 361-368. DOI:10.1016/j.engfailanal.2009.08.002.

[4] Wanlin, G. (1993). Elastic-plastic analysis of a finite sheet with a cold worked hole, Eng. Fract. Mechanics, 46(3), pp. 857-864. DOI:10.1016/0013-7944(93)90238-n.

[5] Ball, D.L. (1995). Elastic-plastic stress analysis of cold expanded fastener holes, Fatigue and Fract.of Eng. Mat. and Struct., 18(1), pp. 47-63.

[6] Zhang, Y., Fitzpatrick, M.E., Edwards, L. (2005). Analysis of the residual stress around a cold-expanded fastener hole in a finite plate, Strain, 41(2), pp. 59-70. DOI:10.1111/j.1475-1305.2005.00181.x.

[7] Pavier, M.J., Poussard, C.G.C., Smith, D.J. (1997). A finite element simulation of the cold working process for fastener holes, J. of Str. Analysis, 32, pp. 287-300. 
[8] Pavier, M.J., Poussard, C.G.C., Smith D.J. (1999). Effect of residual stress around cold worked holes on fracture under superimposed mechanical load, Eng. Fract. Mechanics, 63(6), pp.751-773. DOI: 10.1016/s0013-7944(99)00050-8.

[9] Chakherlou, T.A., Vogwell, J. (2004). A novel method of cold expansion which creates near uniform compressive tangential residual stress around a fastener hole, Fatig. \& Fract. of Eng. Mat. \& Struct., 27(5), pp. 343-351. DOI:10.1111/j.1460-2695.2004.00727.x.

[10] Moreira, P.M.G.P., De Matos, P.F.P., Pinho, S.T., Pastrama, S.D., Camanho, P.P., De Castro, P.M.S.T. (2004). The Residual Stress Intensity Factors for Cold-Worked Cracked Holes: a Technical Note, Fatig. \& Fract. of Eng. Mat. \& Struct., 27:879-886. DOI:10.1111/j.1460-2695.2004.00768.x.

[11] Kokaly, M.T., Ransom, J.S., Jude, B.S., Restis, H., Reid, L. (2005). Predicting fatigue crack growth in the residual stress field of a cold worked hole, J. ASTM Int., 2, pp. 119-131.

[12] Yongshou, L., Xiaojun, S., Jun, L., Yue Zhufeng. (2010). Finite element method and experimental investigation on the residual stress fields and fatigue performance of cold expansion hole, Materials and Design; 31(3), pp. 1208-1215. DOI:10.1016/j.matdes.2009.09.031.

[13] Garcia-Granada, A.A., Pavier, M.J., Smith, D.J. (2001). A new procedure based on Sachs' boring for measuring nonaxisymmetric residual stresses, Int. J. of Mech. Sciences, 42(6), pp. 1027-1047. DOI:10.1016/s0020-7403(99)00039-9.

[14] Garcia-Granada, A.A., Pavier, M.J., Smith, D.J. (2001). A new procedure based on Sachs' boring for measuring nonaxisymmetric residual stresses: experimental application, Int. J. of Mech. Sciences, 43(12), pp. 2753-2768. DOI:10.1016/s0020-7403(01)00071-6.

[15] Özdemir, A.T., Edwards, L. (2004). Through-thickness residual stress distribution after the cold expansion of fastener holes and its effects on fracturing, J. Eng. Mater. Technol., 126, pp. 129-135.

[16] Zuccarello, B., Di Franco, G. (2013). Numerical-experimental Method for the Analysis of Residual Stresses in Coldexpanded Holes, Exp. Mechanics; 53(4), pp. 673-686. DOI:10.1007/s11340-012-9669-2.

[17] Ball, D.L., Lowry, D.R. (1998). Experimental investigation on the effects of cold expansion of fastener holes. Fat. \& Fract. of Eng. Mat. \& Struct., 21(1), pp. 17-34. DOI:10.1046/j.1460-2695.1998.00430.x.

[18] Lacarac, V.D., Smith, D.J., Pavier, M.J., Priest, M. (2000). Fatigue crack growth from plain and cold expanded holes in aluminium alloys, Int. J. of Fatigue; 22(3), pp.189-203. DOI:10.1016/s0142-1123(99)00126-7.

[19] Lacarac, V.D., Smith, D.J., Pavier, M.J. (2001). The effect of cold expansion on fatigue crack growth from open holes at room and high temperature, Int. J. of Fatigue, 23, pp.161-170. DOI:10.1016/s0142-1123(01)00125-6.

[20] Clark, G. (1991). Modeling of residual stresses and fatigue crack growth at cold-expanded fastener holes, Fat. \& Fract. of Eng. Mat. \& Struct., 14(5), pp.579-589. DOI:10.1111/j.1460-2695.1991.tb00684.x.

[21] Lei, Y., O’Dowd, N.P., Webster, G.A. (2000). Fracture mechanics analysis of a crack in a residual stress field, Int. J. of Fract, 106, pp.195-216.

[22] Grandt, Jr. A.F., Kullgren, T.E. (1983). Tabulated stress intensity factor solutions for flawed fastener holes, Eng. Fract. Mech., 18(2), pp.435-451. DOI:10.1016/0013-7944(83)90152-2.

[23] Lin, X.B., Smith, R.A. (1998). Fatigue shape analysis for corner cracks at fastener holes, Eng. Fract. Mech., 59(1), pp. 73-87. DOI:10.1016/S0013-7944(97)00085-4.

[24] de Rijck, J.J.M., Fawaz, S.A. (2001). Stress intensity factors and crack interaction in adjacent holes, Eng. Fract. Mech., 68(7), pp. 963-969. DOI:10.1016/s0013-7944(00)00113-2.

[25] Stefanescu, D. (2004). Measurement and prediction of fatigue crack growth from cold expanded holes. Part 2: prediction of fatigue crack growth from cold expanded holes, J. of Strain Analysis, 39(1), pp. 41-53. DOI:10.1177/030932470403900104.

[26] de Matos, P., McEvily, A., Moreira, P., de Castro, P. (2006). Analysis of the effect of cold working of rivet holes on the fatigue life of aluminum alloy, Int. J. of Fract., 29(3), pp. 575-586. DOI:10.1016/j.ijfatigue.2006.04.004.

[27] Stuart, D.H., Hill, M.R., Newman, J.C. (2011). Correlation of one-dimensional fatigue crack growth at cold-expanded holes using linear elastic fracture mechanics and superposition, Eng. Fract. Mech., 78(7), pp. 1389-1406. DOI:10.1016/j.engfracmech.2011.02.016.

[28] Lacarac, V.D., Garcia-Granada, A.A., Smith, D.J., Pavier, M.J. (2004). Prediction of the growth rate for fatigue cracks emanating from cold expanded holes, Int. J. of Fatigue 26(6) pp. 585-595. DOI:10.1016/j.ijfatigue.2003.10.015

[29] Pasta, S. (2007). Fatigue crack propagation from a cold-worked hole, Eng. Fract. Mech. 74(9), pp. 1525-1538. DOI:10.1016/j.engfracmech.2006.08.006.

[30] Backman, D., Cowal, C., Patterson, E.A. (2010). Analysis of the effects of cold expansion of holes using thermoelasticity and image correlation, Fat. \& Fract. of Eng. Mat. \& Struct., 33(12), pp. 859-870.

DOI:10.1111/j.1460-2695.2010.01472.x. 
[31] Keith, W.J., Ralph, W.B. (2017). Investigation of residual stress relaxation in cold expanded holes by the slitting method, Eng. Fract. Mech., 179, pp. 213-224. DOI:10.1016/j.engfracmech.2017.05.004.

[32] Prime, M.B. (1999). Measuring Residual Stress and the Resulting Stress Intensity Factor in Compact Tension Specimens, Fat. \& Fract. of Eng. Mat. \& Struct., 22(3), pp. 195-204. DOI:10.1046/j.1460-2695.1999.00155.x.

[33] Schindler, H.J. (1995). Determination of residual stress distributions from measured stress intensity factors, Int. J. of Fract., 74(2), pp. R23-R30. DOI:10.1007/bf00036266.

[34] Schindler, H.J., Cheng, W., Finnie, I. (1997). Experimental determination of stress intensity factors due to residual stresses. Exp. Mech., 37(3), pp. 272-277. DOI:10.1007/bf02317418.

[35] Matvienko, Y.G., Pisarev, V.S., Eleonsky, S.I., Chernov, A.V. (2014). Determination of fracture mechanics parameters by measurements of local displacements due to crack length increment, Fat. \& Fract. of Eng. Mat. \& Struct., 37(12), pp. 1306-1318. DOI:10.1111/ffe.12195.

[36] Pisarev, V.S., Matvienko, Y.G., Eleonsky, S.I., Odintsev, I.N. (2017). Combining the crack compliance method and speckle interferometry data for determination of stress intensity factors and T-stresses, Eng. Fract. Mech., 179, pp. 348374. DOI:10.1016/j.engfracmech.2017.04.029.

[37] Shchepinov, V.P., Pisarev, V.S., Novikov, S.A., Balalov, V.V., Odintsev, I.N., Bondarenko, M.M. (1996). Strain and stress analysis by holographic and speckle interferometry, Chichester: John Wiley.

[38] Peterson, R.E. (1974). Stress concentration factors. Charts and relations useful in making strength calculations for machine parts, New-York: John Wiley.

[39] Boni, L., Fanteria, D., Lanciotti, A., Polese, C. (2013). Experimental and analytical assessment of fatigue and crack propagation in cold worked open hole specimens, Fat. \& Fract. of Eng. Mat. \& Struct., 36(9), pp. 930-941.

DOI:10.1111/ffe.12050. 